\title{
2015 James Ewing Lecture: 75-Year History of the Society of Surgical Oncology_Part III: The Transformative Years (1991-2015)
}

\author{
Charles M. Balch, $\mathrm{MD}^{1}$, Daniel G. Coit, $\mathrm{MD}^{2}$, and Russell S. Berman, $\mathrm{MD}^{3}$ \\ ${ }^{1}$ Department of Surgery, University of Texas Southwestern Medical Center, Dallas, TX; ${ }^{2}$ Memorial Sloan-Kettering \\ Cancer Center, New York, NY; ${ }^{3}$ Department of Surgery, New York University School of Medicine, New York, NY
}

The first 50 years of the Society of Surgical Oncology (SSO) have been described for the traditional years (19401965) and the transitional years (1966-1990). ${ }^{1,2}$ The period 1991-2015 were transformative, both for the SSO and for the specialty of surgical oncology. During this last quarter century, the SSO grew and matured as a global leader, representing the educational and professional interests of surgical oncologists throughout the world. Photos of the SSO presidents during this era are shown in Fig. 1. After years of deliberation and planning, surgical oncology finally achieved recognition as a defined subspecialty with board certification and widespread adaptation of multidisciplinary cancer care throughout the surgical oncology community.

Although surgical oncology was flourishing in many academic centers at the end of the previous quarter century (1985-1990), the Society appeared temporarily to have lost its momentum, ending at a low ebb. ${ }^{3}$ The board minutes in 1989 and 1990 reported that active membership and meeting attendance were declining, fellowship programs were not growing, the 1989 budget was in deficit, and the Society was experiencing a negative cash flow. ${ }^{4}$ But the mission of the Society and the resolve of its leadership prevailed, and the SSO moved into a transformative period of growth in all its dimensions. During the next 3 years, from 1991 to 1994, the presidential leadership of Drs. Ketcham, Balch, and Morton successfully engaged the

\footnotetext{
(C) Society of Surgical Oncology 2016
}

First Received: 8 November 2015;

Published Online: 28 January 2016

C. M. Balch, MD

e-mail: charles.balch@utsouthwestern.edu society in a complete reorganization of its annual meeting and its administration. The Society boldly initiated new programs and activities that were attractive to the entire surgical oncology community, especially younger surgeons who had previously not related to the SSO as their primary professional society. ${ }^{1}$

This reengineering process began with a 2-day strategic planning retreat held at MD Anderson Cancer Center in January 1990, with more than 25 members comprising past and then current leadership in the Society. From that meeting, the SSO transformed itself in a new direction while maintaining its traditions and heritage. The annual meeting was completely reorganized in a format that still stands currently. To ensure input to the Executive Council from younger members, three councilor-at-large positions restricted to those younger than 45 years were added to the Executive Council, and for the first time, by election of the membership. ${ }^{2}$ To provide financial support for expanding the scope of the annual meeting, corporate sponsorship and exhibits were added as a new source of meeting revenue and educational offerings. Plans were initiated to establish a new journal owned by the SSO. The SSO hired a new management team and committed to the development of a reserve fund equivalent to 1 year's operating expense. Membership criteria were made more inclusive, expanded to include surgeons who did not have formal training in surgical oncology but were qualified "with six years of continuous practice in surgical oncology." Surgeons completing an SSO-approved training program could become members immediately as "candidate members."

\footnotetext{
${ }^{1}$ For additional insight, see the verbal history of the SSO from living past presidents on the SSO website (http://www.surgonc.org/).

2 The first three elected councilors-at-large were Drs. John Daly, Jeffrey Norton, and Nicholas Petrelli.
} 

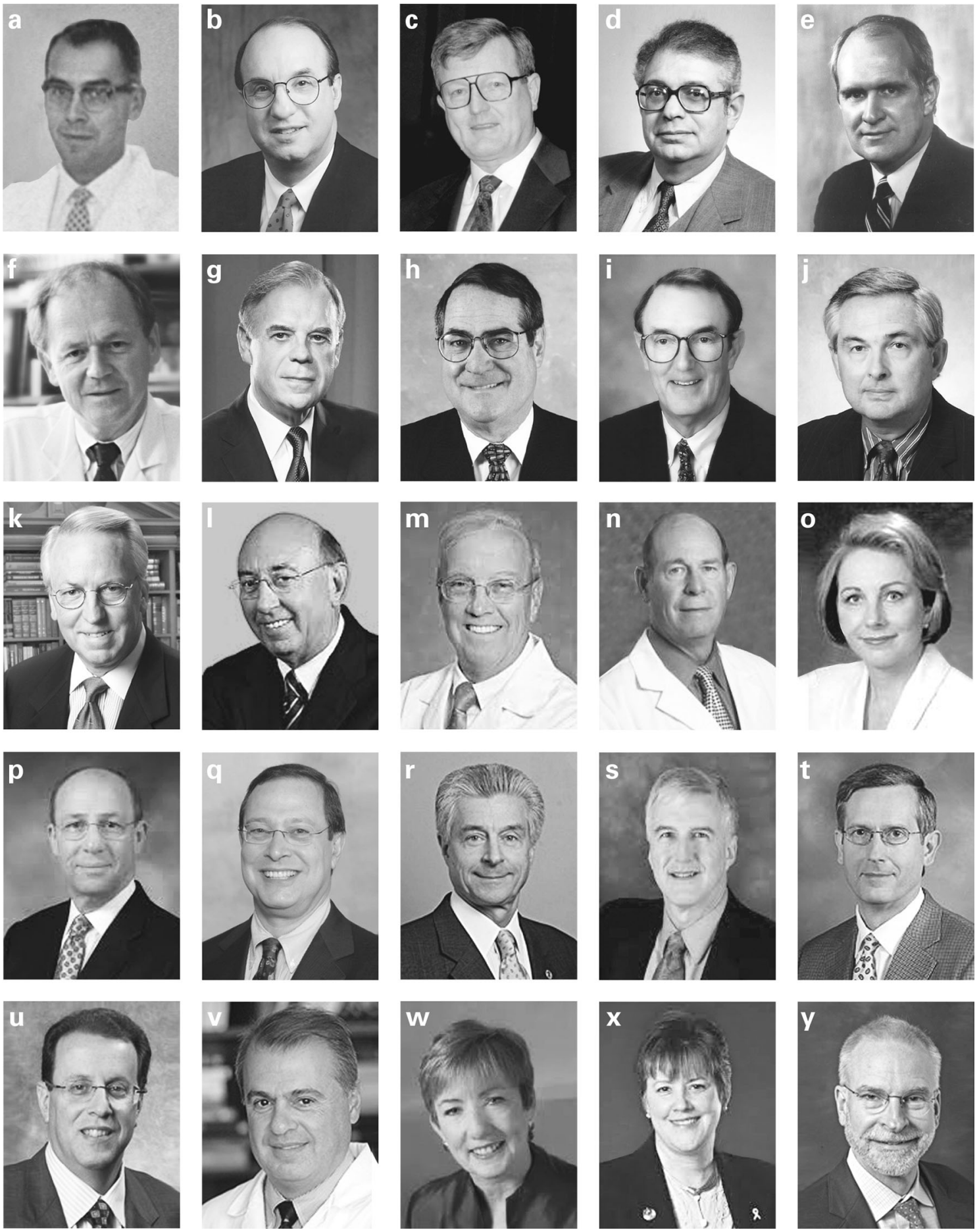

FIG. 1 Presidents of the Society of Surgical Oncology 1990-2015. (a) Alfred S. Ketcham, MD, 1990-1991. (b) Charles M. Balch, MD, 1991-1992. (c) Donald L. Morton, MD, 1992-1993. (d) Samuel A. Wells, Jr, MD, 1993-1994. (e) Bernard Gardner, MD, 1994-1995. (f) Murray F. Brennan, MD, 1995-1996. (g) Kirby I. Bland, MD, 19961997. (h) David P. Winchester, MD, 1997-1998. (i) Edward M. Copeland III, MD, 1998-1999. (j) Glenn D. Steele, Jr, MD, PhD, 1999-2000. (k) William C. Wood, MD, 2000-2001. (l) John E. Niederhuber, MD, 2001-2002. (m) John M. Daly, MD, 2002-2003. (n) Alfred M. Cohen, MD, 2003-2004. (o) S. Eva Singletary, MD, 2004-2005. (p) Timothy J. Eberlein, MD, 2005-2006. (q) Raphael E. Pollock, MD, PhD, 2006-2007. (r) Nicholas J. Petrelli, MD, 20072008. (s)William G. Cance, MD, 2008-2009. (t) Fabrizio Michelassi, MD, 2009-2010. (u) Mitchell C. Posner, MD, 2010-2011. (v) James S. Economou, MD, PhD, 2011-2012. (w) Monica Morrow, MD, 2012-2013. (x) V. Suzanne Klimberg, MD, 2013-2014. (y) Ronald J. Weigel, MD, PhD, 2014-2015 
TABLE 1 Society of Surgical Oncology from 1992 to 2012: 20 years of growth

\begin{tabular}{lll}
\hline & 1992 & 2012 \\
\hline Members & 1078 & 2694 \\
Annual meeting & 767 & 1629 \\
Attendees & & \\
Corporate \$ & 20,000 & 954,000 \\
Operating budget (\$) & 440,750 & $3,490,585$ \\
Fellowship & 7 (surgical oncology) & 19 (surgical oncology) \\
Training sites & 0 (breast) & 32 (breast) \\
Fellows & 24 (surgical oncology) & 51 (surgical oncology) \\
& 0 (breast) & 43 (breast) \\
\hline
\end{tabular}

There was a tremendous response by the surgical oncology community to these strategic plans as they were implemented during the next few years. The SSO began a new trajectory of growth at a pace that far exceeded expectations, with record growth in membership, meeting attendance, and finances. For example, 147 new members joined the SSO in 1991, the first year after promulgation of the changes in strategic direction. Another important event occurred in October 1991, when the SSO held its Fellowship Matching Program among the 10 SSO-approved training institutions.

A great deal of credit for the successful implementation of these strategies goes to Mr. Jim Slawny and his management team, hired in 1992. The growth and vitality of the SSO as an organization is portrayed in the impressive data showing growth of the organization in all its spheres of activities including membership, meeting attendance, training programs, and especially achievement of financial success well beyond our expectations (Table 1).

TABLE 211 Seminal events in SSO history

1940: Formation of the James Ewing Society in New York City 1948: First Annual Cancer Symposium of the James Ewing Society 1966: First Presidential Address by Glenn H. Leak

1975: James Ewing Society renamed the Society of Surgical Oncology

1983: First surgical oncology fellowship training program approved

1994: Launch of the SSO journal Annals of Surgical Oncology

2003: First Breast Oncology Fellowship training program approved

2010: First "Best of SSO" presented by the Mexican Oncology

Society

2011: First Fellows Institute program in Cincinnati Ohio

2011: American Board of Surgery approved SO subspecialty certification

2012: SSO administration moves to self-management

\section{LAUNCH OF THE ANNALS OF SURGICAL ONCOLOGY IN 1994}

Historically, the Society had published its presidential addresses and James Ewing lectures in the journal Cancer from 1966 to 1985, and then in the Archives of Surgery from 1986 to $1992 .{ }^{5}$ Limitations about publishing in these journals led the SSO, after 2 years of planning, to launch its own Journal, the Annals of Surgical Oncology (ASO) in January 1994 (Table 2). ${ }^{6}$ Dr. Robert Beart chaired the Publications Committee and had an important role in leading this effort. The Executive Council asked Dr. Balch to become its first and only Editor-in-Chief to date. The success of this journal through the subsequent years resulted from the joint leadership and collective wisdom of the journal's first editors (Fig. 2). During the next several years, the Journal succeeded in size and value well beyond initial expectations. The success was due to a fully engaged editorial board and participation by surgeons worldwide submitting their best manuscripts. The ASO currently is the largest and most cited journal on the subject in the world. The Journal also has provided millions of dollars to the SSO over the years to invest in other types of membership benefits and in the financial vitality of the organization.

The ASO has become a truly global journal, paralleling the SSO's strategic initiatives to become a global society. ${ }^{7-9}$ The ASO has migrated from a traditional print journal to one with an electronic strategy that allows medical institutions and libraries around the world to access it. The ASO currently is available in more than 10,000 institutions and libraries in 105 countries.

As a benchmark of the ASO's educational value, we measure full text downloads each year. In 2014, more than 549,000 downloads occurred, equivalent to more than 4 million pages of printed text in 1 year! Surgeons who submit manuscripts to the Journal are from all regions of the world. Great credit goes to the editorial board, to the more than 2000 reviewers of manuscripts, and to our publisher, Springer, in New York City.

\section{TURN OF THE 21ST CENTURY}

As the 20th century ended, the SSO — under the leadership of Presidents Wells, Gardner, Brennan, Bland, Winchester, and Copeland (Fig. 1)—expanded its emphasis on multidisciplinary cancer management, clinical trials, postgraduate education, and subspecialty training.

One seminal event was the initiation of the breast oncology fellowships (in partnership with the American Society of Breast Surgeons and the American Society of Breast Disease) in 2003 (Table 2). ${ }^{10}$ The University of Texas Southwestern Medical Center became the first 

Surgical Oncology (left to right): Charles Balch (Editor-in-Chief), Mark Roh (Executive Editor), associate editors Murray Brennan, Ted Copeland, and Donald Morton; Robert Beart (Chair of the Publications Committee)
FIG. 2 First leadership of Annals of

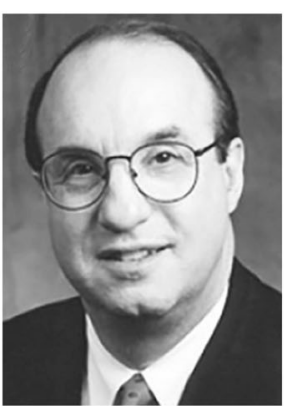

Charles Balch

Editor-in-Chief

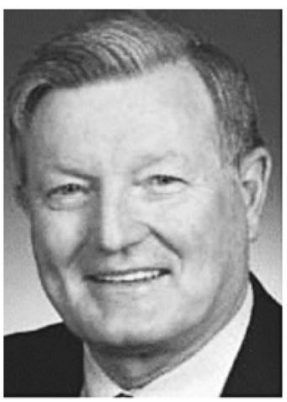

Donald Morton Associate Editor

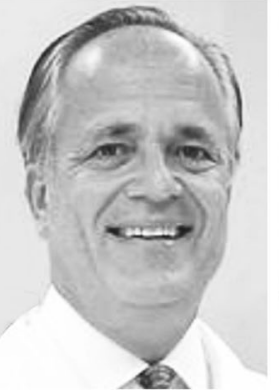

Mark Roh

Executive Editor

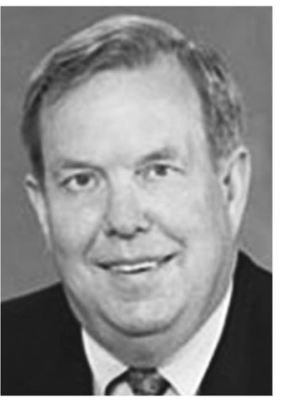

Robert Beart

Chair, Publications

Committee

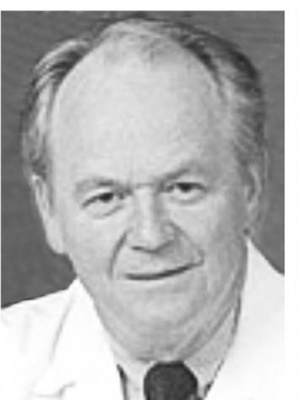

Murray Brennan Associate Editor

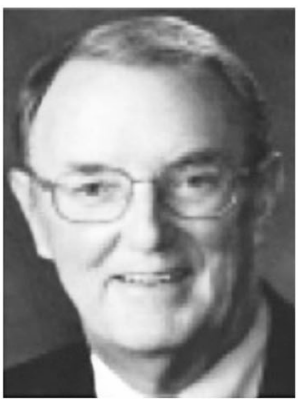

Ted Copeland

Associate Editor program to be site visited and approved. The site-visit leader was Dr. Scott H. Kurtzman, Chairman of the SSO Training Committee (Fig. 3).

During the next 7 years, under the leadership of SSO Presidents Steele, Wood, Niederhuber, Daly, Cohen, Singletary, and Eberlein (Fig. 1), the SSO continued to expand its impact, with new educational initiatives to educate around themes of conducting clinical research, a broader educational portfolio, and more inclusive membership criteria.

In 2006, under the leadership of President Raphael Pollock, the SSO conducted a thorough inventory of its programs and adopted an ambitious strategic plan for 2007-2010. ${ }^{11}$ As described by President Mitchell Posner, "this was an extraordinary effort that brought the SSO to a level of prosperity from a scientific, educational, and financial standpoint that heretofore was unmatched." 12 Two important outcomes of this planning were the launch of the Clinical Investigator Awards and the formation of two new committees: the Community Surgical Oncology Committee, first headed by Dr. Peter Beitsch from Dallas, Texas, USA, and the International Committee, first led by Dr. Joseph Klausner from Tel Aviv, Israel. ${ }^{12}$

Two seminal events occurred in 2010 and 2011 (Table 2). In 2010, the first "Best of SSO" was held in Cancun Mexico, organized by the Mexican Oncology Society and the National Cancer Institute of Mexico under the leadership of Dr. Hector Martinez Said. Currently, the
"Best of SSO" is in its sixth consecutive year (Fig. 4). The success of this program set the stage for similar programs in other countries including India, Egypt, and Brazil. In 2011, the SSO launched the Fellows Institute, ${ }^{3}$ which attracted the majority of surgical oncology and breast fellows in the United States, Mexico, and Canada. This program has provided hands-on experience with both the technical aspects of surgical management and clinical approaches to multidisciplinary cancer care. ${ }^{9,10}$

As the SSO grew and diversified both in membership and programs under the leadership of Presidents Pollock, Petrelli, Cance, and Michelassi, (Fig. 1), it became evident that more changes would be necessary if the SSO were to maintain a leadership role. During 2 years (2010 and 2011), Dr. Mitchell Posner led a series of strategic planning initiatives involving scores of SSO leaders and staff. Indeed, this was the most data-driven and detailed process the Society had ever conducted (Posner, 2012, Economou, 2012, Morrow 2013). This included a first-ever Strategic Retreat focused entirely on enduring educational products, led by Presidents Suzanne Klimberg and Ronald Weigel (Klimberg, 2014). The details are described in presidential addresses by Drs. Posner, Economou, Morrow, Klimberg, and Weigel. ${ }^{8,9,12,13}$

\footnotetext{
${ }^{3}$ Led by Suzanne Klimberg, Charles Cox, David Bartlett, Jill Deitz, and Charles Scoggins
} 


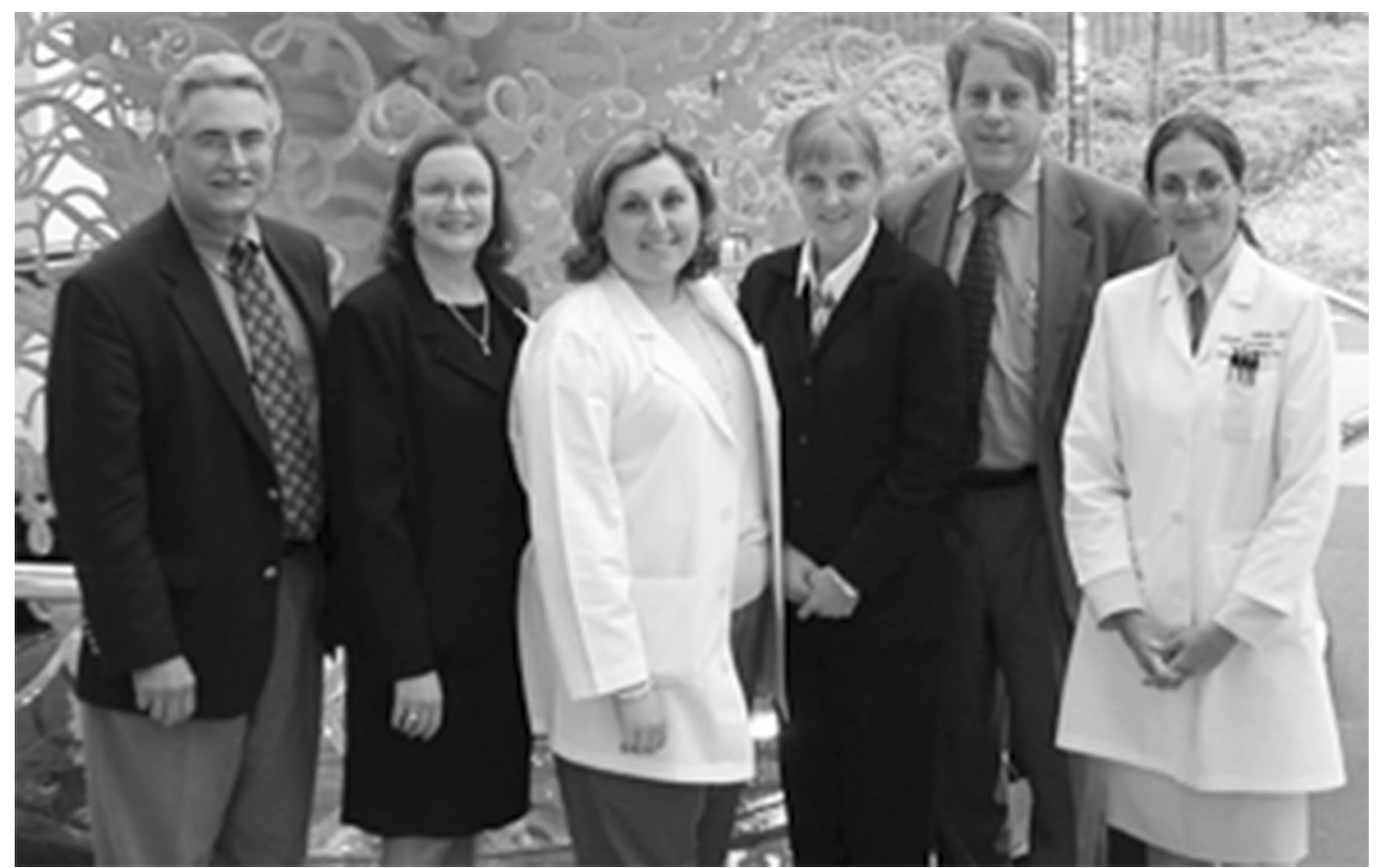

FIG. 3 First site visit of Breast Fellowships in 2003 by the Society of Surgical Oncology (SSO) in partnership with the American Society of Breast Surgeons (ASBS) and the American Society of Breast Disease (ASBD) at the University of Texas Southwestern Medical Center

As described by President Jim Economou in 2012, "the Posner Strategic Plan recognized the need to create a big tent for all cancer surgeons, to reorganize and reinvigorate its governance, to create an independent administrative organization, and to greatly enhance education and training for surgical oncologists at all stages in their careers." 8 President Monica Morrow added the perspective that "what we really were attempting to do was to change the culture of the SSO from that of a society that put on an annual meeting and provided oversight for fellowship
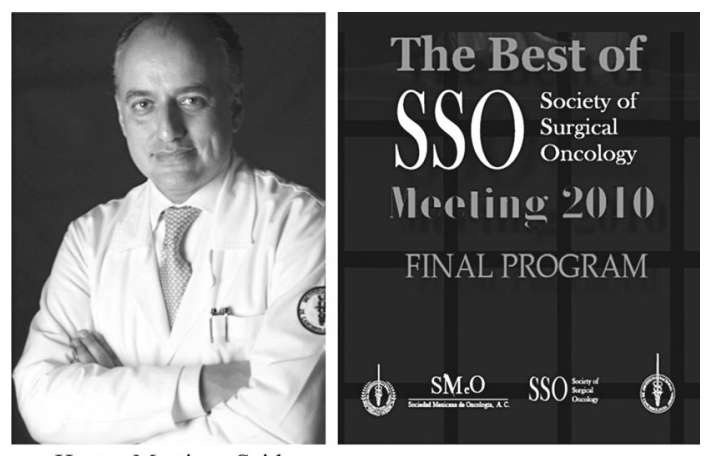

FIG. 4 First "Best of SSO" organized by the National Cancert Institute of Mexico and the Mexican Oncology Society under the leadership of Dr. Hector Martinez Said
(UTSW), the first program to be approved. In the photo (left to right) are Drs. John Coscia (ASBD), Anne Spangler (UTSW), Susan Hoover (UTSW), Tricia Kelley (ASBS), Scott Kurtzman (Chair of the SSO Training Committee), and Elizabeth Naftalis (UTSW)

programs to a modern, full-service surgical organization that addressed the spectrum of member needs." 13

\section{THE LAST 5 YEARS (2010-2015)}

During the last 5 years of SSO history, Presidents Posner, Economou, Morrow, Klimberg, and Weigel (Fig. 1), as well as their Executive Councils and Committee Chairs, have led the continued growth and value of the Society to address the professional needs of an increasing and more diverse membership. The Educational Retreat held in December 2001 prioritized the educational strategies of the SSO for the next several years. The SSO currently has become a full-fledged educational society whose membership value goes beyond, but still is complementary to, the traditional three pillars: the Annual Meeting, the ASO, and the SSO-approval of Surgical Oncology Fellowship programs. Their contributions are many, summarized as follows:

- Membership that is larger, more inclusive, and diverse.

- Designated Executive Council positions representing community and international surgeons.

- Broad educational agenda with new educational products (e.g.: Surgical Oncology Self-Assessment Program [SOSAP], virtual meeting, maintenance of certification products). 
- Hiring of Dr. Charmaine Cummings, a nurse oncologist with a $\mathrm{PhD}$ in education, as the Director of Education.

- Improved financial and budgeting oversight.

- New website launched in 2015.

- Reorganization of the James Ewing Foundation to become the SSO Foundation as the sole fund-raising arm of the SSO.

- Move to self-management to broaden staffing skills and experience to implement the expanded strategic agenda.

The Society has worked strategically to become a global leader, with joint programs engaging surgical oncology societies in the countries of South America, Asia, and Europe. ${ }^{9,10}$ These include joint educational sessions, a joint meeting, international exchanges, and the "Best of SSO." We currently have a full-time staff person to help implement the growing activity of international affairs.

An important expansion of SSO value was the creation of SOSAP, led by President Ronald Weigel and modeled after the very successful self-assessment program offered by the American College of Surgeons. ${ }^{8,10}$

\section{MOVE TO SELF-MANAGEMENT}

The next to the last of our historical highlights was the SSO move to self-management (Table 2). ${ }^{8,10,13}$ This was a big change and an important strategy aimed at enabling volunteers and paid staff to better manage and broaden our scope of activities into a full-fledged professional organization. As President Monica Morrow said, “The transition itself was an enormous amount of work. If we had actually had any idea of the magnitude of the job, we might never have opted to move to self-management, and certainly not with the very aggressive time schedule we chose." ${ }^{13}$ But could we make that transition and hire an even better management team than we had before with contracted services?

Under the leadership of Dr. James Economou and Monica Morrow, the transition team ${ }^{4}$ worked tirelessly during 12 months. ${ }^{8,13}$ A great deal of credit for the success goes to our first employee of the SSO, Ms. Eileen Widmer, who took the risk with us to establish new management and administrative services, together with Ms. Kathy Bell and Dr. Charles Balch, who were contracted to help out during the 12-month transition. The committee was charged to hire staff, locate a new office, and establish a new website and new information systems while providing all the services SSO members enjoy without any disruption during those critical 12 months of transition until the SSO moved

\footnotetext{
${ }^{4}$ Drs. Monica Morrow (Chair), Daniel Coit, Charles Balch, Mitchel Posner, and Eileen Widmer
}

into its new headquarters in Rosemont, Illinois, close to O'Hare International Airport (Weigel 2015). ${ }^{10}$ The transition was completed on time and under budget!

\section{THE 75-YEAR HISTORY OF SURGICAL ONCOLOGY BOARD CERTIFICATION}

This seminal event in the history of the SSO to date was saved for last because, historically, specialty board recognition was an original strategy of the founding fathers and continued to be one of the top agenda items throughout our 75-year history (Table 2). Indeed, it is truly remarkable that the Society leaders pursued this objective during the course of 75 years from its original vision to its final implementation.

One of the three original purposes of the Society was "to seek to gain recognition of cancer as a specialty by the medical profession" as first described in our Constitution in November $1940 .{ }^{1}$ The James Ewing Society Board minutes mentioned this goal in $1946,{ }^{14}$ as well as the presidential addresses by Robert Schweitzer in $1974,{ }^{15}$ William Guiss in 1976, ${ }^{16}$ and Harvey Baker in 1978. ${ }^{17}$ Condict Moore devoted his entire presidential address in 1981 to definition of a surgical oncologist. ${ }^{18}$

Despite multiple discussions and exhortations, little progress was made in getting the American Board of Surgery (ABS) to recognize the specialty of surgical oncology. As a result, the SSO leadership decided to move forward more aggressively to approve a larger number of fellowship training programs and to issue its own certificate to approved training programs. ${ }^{19}$

In 1985, under the leadership of President Dr. Hiram Polk, an Examination Committee chaired by Dr. Charles Balch was tasked with developing a certifying exam. We hired the National Board of Medical Examiners and were fully prepared to administer the initial examination in 1986 to graduates of SSO training programs during the previous 6 years, and a second exam in 1988 that would be open to all surgical members of the SSO. These actions did get the attention of the ABS, which then named the SSO as a sponsoring organization with designated Board membership, starting in $1983 .^{5}$

\section{FIRST ATTEMPTS AT BOARD RECOGNITION OF SURGICAL ONCOLOGY}

The first serious attempt to establish formal recognition of surgical oncology as a subspecialty was in 1987, when the Board agreed to give "serious consideration" to issuing a certificate of added qualifications in surgical oncology. In

\footnotetext{
5 The SSO representatives to the ABS were Drs. Charles Balch (1986-1992), John Daly (1992-1998), Timothy Eberlein (19982004), Ronald Weigel 2004-2010), and Douglas Tyler (2010-2015).
} 
response, the SSO agreed to suspend its examination and not expand its training programs.

However, in 1989, after considerable planning and debate, the Board rejected the original proposal to issue more certificates of Added Qualification. They handed over the curriculum content to their Surgical Oncology Task Force $^{6}$ and encouraged the SSO to maintain its high standards of fellowship training in case the Board wanted to reconsider this issue in later years. The SSO leadership and program directors did adopt these new and expanded guidelines for surgical oncology training, based in part on these documents from the American Board of Surgery Task Force. Importantly, the Board recognized surgical oncology as one of the 10 primary components of general surgery training and cognitive knowledge. They also incorporated new surgical oncology questions and clinical scenarios into their examination process. ${ }^{19}$

During the next 10 years, the SSO continued to approve more training programs and used the written exam as an intraining examination for fellows to provide national benchmarks for training directors. It would take 20 years for the collegial relationships between the SSO and the general surgery leadership to be rewarded by the unanimous vote of the ABS in favor of pursuing a subspecialty certificate in advanced surgical oncology. ${ }^{20}$ During this time, many SSO members rose to leadership roles in American surgery. Indeed, many SSO members have served as directors of the ABS, and 10 have served as chairs of the ABS Board of Directors, ${ }^{7}$ undeniably the highest honor an ABS director can achieve. ${ }^{21}$

The stars were aligned in 1999, when the ABS invited the SSO to nominate members to a new Surgical Oncology Advisory Council (SOAC), which could officially represent surgical oncology issues, including the prospects of reexamining the issue of subspecialty recognition. ${ }^{8}$ Outgoing SSO President Edward Copeland nominated Drs. Winchester, Coit, and Townsend, which the Board accepted, and added Glenn Steele as the SOAC chairman. ${ }^{22}$ There was a unique confluence of national leadership at that time because Dr. Copeland was previously Chair of the ABS (1990-1991) and subsequently President of the SSO

\footnotetext{
${ }^{6}$ The ABS ad hoc Committee on Surgical Oncology established in 1986 consisted of Drs. James Carrico (Chair), J. Bradley Aust, Charles Balch, Murray Brennan, Edward Copeland, Bernard Jaffe, Scott Jones, LeSalle Leffall, and Paul Weeks.

7 The SSO members who have served as chairmen of the ABS directors are Drs. William Longmire (1961-1962), Claude Organ Jr (1984-1086), Samuel Wells Jr (1988-1989), Edward Copeland (1990-1991), Andrew Warshaw (1992-1993), Jay Grosfeld (19961997), Glenn Steele Jr (1999-2000), Barbara Bass (2004-2005), Courtney Townsend Jr (2006-2007), and Steven Stain (2009-2010). ${ }^{19}$

8 The chairs of the SOAC to the ABS were Drs. Glenn Steele (19992000), Timothy Eberlein (2000-2004), Marshall Urist (2004-2005), Carlos Pellegrini (2005-2009), and Fabrizio Michelassi (2009-2012).
}

(1998-1999), whereas Dr. Steele was Chair of the ABS (1999-2000) and also the incoming President of the SSO (1999-2000).

\section{SECOND AND SUCCESSFUL ATTEMPT AT BOARD RECOGNITION}

Nine years later, a robust proposal for a subspecialty certificate in advanced general surgical oncology was created. This proposal was voted on by the directors of the ABS and approved unanimously in June 2009, and Dr. Michelassi was elected as Chair of the SOAC. ${ }^{20}$ Dr. Michelassi's election as Chair of SOAC guaranteed that all necessary subsequent steps to make the certificate a reality could be undertaken successfully. During the next 3 years, the ABS submitted a formal request to the American Board of Medical Specialties (ABMS) to establish a certificate in Complex General Surgical Oncology. The request was approved on 23 March 2011. This was a significant event for both the specialty of surgical oncology and the ABS in that this certificate was the first new certificate offered by the ABS in more than 20 years. ${ }^{20}$ In recognition of this milestone achievement, the ABS changed the name of the Surgical Oncology Advisory Council (SOAC) to the Surgical Oncology Board (SOB), with Fabrizio Michelassi elected as the first chair of the SOB. Further details of the many people who contributed to the successful run-up to board certification can be found in Fabrizio Michelassi's SSO Presidential Address in 2010 and his two subsequent editorials in the Annals of Surgical Oncology. ${ }^{19-21}$

During the course of the next year, the Residency Review Committee in Surgery (RRC-S) was asked by the Accreditation Council on Graduate Medical Education (ACGME) to specify the training requirements for surgical oncology programs. The SSO was asked by the RRC-S to select a representative to join the working RRC-S subcommittee, and Dr. Russell Berman was selected for this important task. ${ }^{20,21}$ The full Board of Directors of the ACGME approved the program requirements in June 2012, opening the way for the first certificates in Complex General Surgical Oncology to be awarded.

The SOB decided to award the certificate of Complex General Surgical Oncology to eligible candidates after they had passed a written qualifying exam and an oral certifying exam, similar to the process leading to a certificate in surgery. ${ }^{20}$ The first cohort of surgical oncology fellows took the written exam in the fall of 2014 and the oral certifying exam in February 2015 to become the first board-certified surgical oncologists,,${ }^{9,10,20}$ exactly 75 years after "the Founding Five" members of the James Ewing Society envisioned the importance of this activity. ${ }^{1}$

Ronald Weigel has described the full implementation of the ABS SOB activities in his SSO Presidential Address. ${ }^{10}$ 
He has provided significant leadership during the past 10 years, serving as the SSO representative to the ABS and leading the creation of a critical educational product from the SSO to trainees and members, the Surgical Oncology Self-Assessment Program (SOSAP). ${ }^{10}$

\section{CONCLUSIONS ON THE 75-YEAR HISTORY OF THE SSO}

Dr. James Ewing was our inspiration. Dr. William MacComb was the pioneer who established the vision for the Society, serving as its president three times, and Dr. Ronald Weigel has ably led the Society as its 71st president, as described in his 2015 Presidential Address. ${ }^{10}$ Many of the living past presidents of the SSO attended this historic meeting to join in the celebration (Electronic Supplement).

Finally, I (C.M.B.) want to thank Daniel Coit, Russell Berman, Karen Hurley, and Kathy Sampson, who worked with me during many months to gather a massive amount of documents and photos and synthesize it into the story I was privileged to present to you as the 66th James Ewing Lecturer.

ACKNOWLEDGMENTS The authors thank Ms. Karen Hurley and Kathy Sampson in the SSO Headquarters Office for their assistance in gathering materials, Drs. Walter Lawrence and Blake Cady for reviewing the manuscript, and Deborah Whippen for editorial assistance.

\section{SIDEBAR I: QUOTES ON THE LEADERSHIP ROLES OF THE SOCIETY OF SURGICAL ONCOLOGY FROM PAST-PRESIDENTS (1991-2015)}

This Society and its members bear a significant responsibility, for the society is the logical organization, by virtue of its membership and focus, to provide the leadership in cancer care, cancer research, and cancer education within both the surgical and oncology community. Balch, $1992^{23}$

...(the SSO should) become more inclusive, by vigorously embracing both US community surgical oncologists as well as surgical oncologists practicing abroad. To be honest, if we continue to view the SSO primarily as the domain of US academic surgical oncologists, we may well be undercutting our ultimate potential for influence. Expanded strength and vitality will come from inclusion and diversity and not by narrowness and exclusivity.... Pollock, $2008^{11}$

I think the most important thing we do is to be an inclusive society...the SSO must become more of an educational machine... we also need to enhance our support for research... as a Society of Surgical Oncology, we must respond as a global leader. We must embrace changes, teach them to all our members, and partner with surgical oncologists in all practices, across the world. Cance, $2010^{26}$

Our specialty is at an inflection point in history occasioned by the unanimous approval of subspecialty board certification by the American Board of Surgery. The 21st century is an exciting time to be a surgical oncologist, with our deeper understanding of cancer biology and a continuous pipeline of molecules...the Annals of Surgical Oncology, is now one of the most important and influential surgical journals. Its prestige has enhanced the international outreach of our society. Economou, $2012^{8}$

What we were really trying to do was to change the culture of the SSO...to a modern, full-service surgical oncology organization that addressed a spectrum of member needs.... We are in the process of changing our governance to be more inclusive, and we are developing new products and services in response to member feedback so that the SSO of the future will be much more than an annual meeting and a journal. Morrow, $2014^{13}$

The Executive Committee and Executive Council worked hard to expand global initiatives and education.... This investment in infrastructure has positioned us to provide what I call translational education.... The SSO has invested over a half million dollars in new educational initiatives.... The reason we can do that has to do with the success of our number one global educational tool...our journal The Annals of Surgical Oncology. Klimberg, $2014^{9}$

The surgical oncologist of the future will no doubt need to remain a surgeon, but he or she will also ne to be a geneticist, a molecular biologist, a bioinformaticist, a pharmacologist, and a radiologist...the SSO needs to create the tools and structure to prepare the next generation to be successful surgical oncologists of the future. Weigel, $2015^{10}$

\section{SIDEBAR II: QUOTES ON THE IMPORTANCE OF MULTIDISCIPLINARY CANCER CARE AND RESEARCH FROM PAST-PRESIDENTS (1991-2015)}

While the centerpiece of our specialty is surgical care for the patient with cancer, the uniqueness of our specialty is oncology management...by the 21st Century it is possible that only a minority of patients with cancer will have surgery alone as a single modality of treatment. It is more likely that chemotherapy and even radiation therapy will be used as the initial cancer treatment for many patients, while surgical treatment for some types of cancer will be relegated to a secondary or even tertiary level. Balch, $1992^{23}$

We must continue to search for new ways to treat cancer, and we have to define surgical oncology research as 
something different from research done by surgeons. Gardner, $1996^{24}$

Surgical Oncology has evolved into a mature surgical discipline with multimodality care at its core. Our roots are still intact.... We must, however, educate all medical professionals about our discipline. Copeland, $1999^{22}$

Our profession needs to emphasize the oncology component of our specialty. We need to take advantage of the primary relationship that we have with our patients.... We need to extend that beyond the operating room. As newer targeted therapies are utilized, it should be the surgical oncologist that feels comfortable administering these medications, which likely will be much less toxic and potentially more effective than existing regimens. Eberlein T. SSO Presidential Address 1996 (personal communication)

What does the postgenomic era mean for surgical oncology? Certainly trainees will need to be well grounded in cancer biology and genetics. There will be a much greater requirement to work in a multidisciplinary fashion in patient care. Cancer therapy of the future will be less toxic.... We as surgeon are going to need to change some of the roles that we play, not just as surgeons, but now more as oncologists. Niederhuber, $2002^{25}$

Surgical oncologists of the future will be board-certified, will have to be trained in multidisciplinary care, and will have an in-depth understanding of cancer biology.... Genetic information about the patient, as well as their tumors, will be used to direct therapy. Molecular and cellular analysis will inform pharmacogenomics to be able to specifically target cancer treatment in an individual patient.... Surgical oncology has a brilliant future, if we are willing to evolve beyond the operative therapy of the patient. Weigel, $2015^{10}$

\section{REFERENCES}

1. Balch CM, Coit D, Berman RS. The 75-year history of the Society of Surgical Oncology: Part I. The traditional years. Ann Surg Oncol. 2015. doi:10.1245/s10434-015-4837-0.

2. Balch CM, Coit D, Berman RS. The 75-year history of the Society of Surgical Oncology: Part II. The transitional years. Ann Surg Oncol. 2015. doi:10.1245/s10434-015-4863-y.

3. Rush BF. Wither, whether, or whither surgical oncology? Arch Surg. 1991;126:302.

4. Winchester DP. Presidential address: The Society of Surgical Oncology and the Commission on Cancer: progress through synergism. Ann Surg Oncol. 1998;5:483-8.
5. Baue A. Welcome to the New England Surgical Society and the Society of Surgical Oncology. Arch Surg. 1985;120:1339-40.

6. Balch CM, Roh MS, Hubona CM. The Annals of Surgical Oncology: an oncology journal for surgeons. Ann Surg Oncol. 1995;274, 849-50.

7. Balch CM, Whippen D, Klimburg VS, Roh M. Annals of Surgical Oncology: the global journal for surgeons treating cancer. Ann Surg Oncol. 2010;17:2255-9.

8. Economou JS. A society in transition: presidential remarks at the 65th Annual SSO Cancer Symposium. Ann Surg Oncol. 2012;19:3293-7.

9. Klimberg VS. Society of Surgical Oncology 2014 presidential address. Ann Surg Oncol. 2014;21:3699-707.

10. Weigel RJ. 2015 Presidential address-Society of Surgical Oncology: the next 75 years. Ann Surg Oncol. 2015;22:2455-61.

11. Pollock RE. Surgical oncology at the crossroads: the future is now. Ann Surg Oncol. 2008;15:661-9.

12. Posner, MC. It's not the destination, it's the journey. 2011 Society of Surgical Oncology presidential address. Ann Surg Oncol. 2012;19:2073-80.

13. Morrow M. The end of the beginning: Society of Surgical Oncology 2013 presidential address. Ann Surg Oncol. 2014;21:1417-25.

14. Dembrow VD. The role of the surgical oncologist in the community hospital: presidential address. Arch Surg. 1986;121:12312.

15. Schweitzer RJ. Surgical oncology: the role in cancer control today. Cancer. 1975;35:592-5.

16. Guiss LW. The surgical oncologist. Cancer. 1977;39:419.

17. Baker HW. The surgical treatment of cancer: The presidential address. Cancer. 1978;43:787-9.

18. Moore C. Definition of an oncologist: presidential address. Cancer. 1981;49:1067-9.

19. Michelassi F. Subspecialty certificate in advanced surgical oncology: 2010 SSO presidential address. Ann Surg Oncol. 2010;17:3094-103.

20. Michelassi F. Update on the American Board of Surgery subspecialty certificate in Complex General Surgical Oncology. Ann Surg Oncol. 2013;20:2103-5.

21. Michelassi F. American Board of Surgery Certificate in Complex General Surgical Oncology: a reality. Ann Surg Oncol. 2011;18:2405-6.

22. Copeland EM. Presidential address. surgical oncology: a specialty in evolution. Ann Surg Oncol. 1999;6:434-432.

23. Balch CM. Presidential address: surgical oncology in the $21 \mathrm{st}$ century. Arch Surg. 1992;127:1272-7.

24. Gardner B. Presidential Address: eat your cereal. Ann Surg Oncol. 1996;3:1-7.

25. Niederhuber JE. Presidential address: the things that matter most. Ann Surg Oncol. 2002;9:709-16.

26. Cance WG. Society of Surgical Oncology presidential address: the war on cancer-shifting from disappointment to new hope. Ann Surg Oncol. 2010;17:1971-8. 